\title{
O corpo carioca desnudado
}

\author{
Nu \& Vestido: dez antropólogos \\ revelam a cultura do corpo \\ carioca.
}

GOLDENBERG, Mirian (Org.).

Rio de Janeiro: Record, 2002. 414 p.

Amanhece no Rio de Janeiro. O sol que surge no horizonte, redondo e quente, reluz nas curvas bem trabalhadas do verde carioca: montanhas, pedras e morros saem aos poucos da sombra para mostrar-se aos olhos do mundo. A cidade maravilhosa contempla-se no espelho d'água de um mar imenso e agradece a Deus, todos os dias, por ter nascido tão bela.

Quem nasce em uma cidade assim, onde as formas da natureza delineiam a fama que atrai a atenção do planeta a cada verão, já vem ao mundo com um sentimento de obrigação: o de se integrar à paisagem. Cumprindo com sua parte, já que a outra só a Deus cabe ajuda, os cariocas acordam cedo e invadem o espaço urbano com suas malhas e lycras coloridas. Logo, logo, estarão andando, correndo, pedalando, 'malhando', e o suor escorrerá pelos seus corpos, cada um no seu estilo.

Ao mesmo tempo, do outro lado do Corcovado, outros cariocas despertam ainda mais cedo e lotam trens, ônibus e vans em busca do pão de cada dia. O suor também escorre ali, só que percorre uma pele que cobre músculos 'sarados' pelo esforço de um dia duro. $O$ bronzeado nem sempre vem da praia; às vezes ele é da cor do trabalho pesado que freqüenta as ruas e avenidas. Misturados, todos os cariocas se esbarram no corre-corre da cidade e ajudam a construir a identidade de um povo que tem no corpo a sua marca e sobre o qual se desenham suas fronteiras.

Os nove artigos organizados pela antropóloga Mirian Goldenberg e reunidos no livro 
Nu \& Vestido: dez antropólogos revelam a cultura do corpo carioca percorrem essas paisagens feitas de corpos e significados.

Já na Apresentação, Mirian Goldenberg sugere, para o que ela chama de "mercado do corpo", o seguinte slogan: "Não existem indivíduos gordos e feios, apenas indivíduos preguiçosos" ( $p$. 9.). O seu trabalho e dos demais antropólogos se propõe a compreender a 'cultura do corpo' e a relacioná-la com a construção de identidades, com o espaço urbano e com as relações sociais que se estabelecem entre gêneros e camadas sociais, usando o Rio de Janeiro como um rico campo de observação e análise. Os autores tratam o corpo carioca como 'fato social'. Construído culturalmente, ele se afasta da natureza e ganha o espaço urbano como "roupa, máscara, veículo de comunicação carregado de signos que posicionam os indivíduos na sociedade" (p. 10).

Inspirada em Claude Lévi-Strauss, autor de O cru e o cozido, Mirian Goldenberg deu o título $\mathrm{Nu}$ \& Vestido a esta coletânea, buscando antecipar aquilo que os artigos desenvolvem tão bem depois: que o corpo 'natural' é, na verdade, 'naturalmente construído'. Daí o culto à 'boa forma' e o 'trabalho' que é feito sobre o corpo 'natural' para torná-lo eternamente jovem e socialmente aceito.

No primeiro artigo, "A civilização das formas: o corpo como valor", Mirian Goldenberg e Marcelo Silva Ramos refletem sobre o uso do corpo como expressão de identidades, levando à sua 'apropriação' por parte do próprio indivíduo, que se submete a cirurgias plásticas, sessões de musculação, tatuagens, piercings, modificações (body modification) e até mesmo ferro quente (branding). Para os autores, essas práticas respondem à crescente necessidade que se impõe na sociedade no sentido de garantir a cada indivíduo um significado próprio, que se revela através de seu corpo.

Fazendo um paralelo com Norbert Elias, os autores identificam um 'processo civilizador' no 'desnudamento' do corpo carioca, que deve estar em conformidade com as regras da 'moral da boa forma'. Assim como os 'trajes de banho' estudados por Elias determinaram, paradoxalmente, a liberdade e um maior controle social sobre os corpos semidesnudados, além de um autocontrole de homens e mulheres, também o corpo nu deve ser livre de "gordura, flacidez e moleza" para ser 'decente'. 'Indecente', de acordo com Mirian Goldenberg e Marcelo Farias, seria o corpo 'fora de forma'.

A 'cultura da malhação', a cirurgia plástica, o consumo de cosméticos e 'de estilos de vida' são, segundo os autores, respostas dos indivíduos às forças sociais, entre elas a mídia e a publicidade, que transformam a 'gordura' em 'doença', o 'ser gordo' em 'desleixo', o 'fora de forma' em 'indecência'.

O artigo revela também como, a partir de uma pesquisa realizada pelos dois antropólogos junto a 1.279 homens e mulheres, as 'camadas médias urbanas' contribuem para a construção das representações sobre a categoria 'corpo': não mais 'natural', mas "coberto de signos distintivos". Aquele que individualiza e, ao mesmo tempo, coletiviza. O 'corpo' é "insígnia", "griffe" e "prêmio". O 'corpo' é, portanto, valor.

$\mathrm{Em}$ "Carioquice ou carioquidade?: ensaio etnográfico das imagens identitárias cariocas", Fabiano Gontijo realiza uma leitura antropológica interessante sobre o Rio de Janeiro, defendendo um 'jeito de ser carioca' que particulariza aspectos da vida social tidos como 'nacionais'.

Utilizando o conceito 'imagens identitárias' para descrever a diversidade da aparência corporal tipicamente carioca - diferente de 'identidades', já que ligado a um processo de construção cultural 'situacional', 'contextual' e 'relacional', o autor percorre a cidade analisando a ocupação do espaço territorial, o hábito de freqüentar a praia e a corporeidade, os modos de vida alternativos, inclusive das comunidades GLS, a prática de esportes, a busca pela saúde física e mental, o circuito musical, o 'ciclo festivo do verão' e o carnaval no Rio de Janeiro.

Particularmente interessante é a forma como o autor explica a oposição cultural entre a Zona Norte e a Zona Sul, baseando-se historicamente na ocupação desses lugares por populações emigrantes. Segundo Gontijo, a divisão territorial define a diversidade cultural e social que existe entre os habitantes não só da Zona Norte e da Zona Sul, mas também do subúrbio da Baixada Fluminense, do Centro e da 'miamizada' Barra da Tijuca, símbolo de ascensão social. Com a chegada de emigrantes estrangeiros e brasileiros primeiro na Zona Norte, formando uma comunidade trabalhadora e operária, criou-se um espaço de oposição para a elite na Zona Sul, que introduziu uma forma diferente de viver a cidade, adotando hábitos praianos. A partir daí, surge a valorização de uma 'morenidade' carioca e o 'ciclo festivo do verão', que inclui as festas de fim de ano, as religiosas e o carnaval.

A partir do crescimento de uma cultura gay no Rio de Janeiro, o autor mostra como a sua diversidade contribui para a valorização do culto ao corpo, de uma vida noturna variada e bastante particular, e de que forma as 'imagens 
identitárias' se relacionam, criando relações sociais que se estabelecem por fronteiras geográficas dentro da cidade.

Gontijo toma por 'carioquidade' a maneira como os cariocas materializam, experimentam e tornam prática social o seu cotidiano e as relações sociais. Daí a 'identidade carioca global', ou 'carioquidade', ser diferente de uma 'identidade nacional brasileira' comumente atribuída ao modo de vida carioca, especialmente a partir de uma imagem típica ligada ao verão e ao carnaval.

O olhar francês de Stéphane Malysse e um certo etnocentrismo propositadamente integrado ao seu ponto de vista dão o tom do artigo "Em busca dos (h)alteres-ego: olhares franceses nos bastidores da corpolatria carioca".

O autor, além de oferecer uma enriquecedora análise sobre a corpolatria no Rio de Janeiro, contribui metodologicamente para a antropologia visual com esse trabalho. Sem receio de lançar mão de seu 'contra-olhar' francês para compreender as funções das imagens corporais na cultura carioca, Malysse dedica sete páginas do artigo para relatar os 'encontros metodológicos' que, como antropólogo, travou com as 'culturas visíveis brasileiras' ligadas ao corpo. Propondo uma "antropologia visual do corpo", o autor procurou "estudar a maneira como os adeptos da corpolatria gerenciam seus corpos e os exibem como sinal", a partir de entrevistas e material audiovisual coletado nos "cenários sociais" e nas próprias casas dos colaboradores, como gosta de chamar (p. 92).

Para Malysse, o corpo (h)altere-ego é uma 'obra-de-arte', um 'parceiro' que reside em um espaço social que fica entre aquilo que podemos e aquilo que devemos fazer com o nosso corpo. O estereótipo corporal, ou "personalidade corporal modal", seria o resultado da incorporação física e psíquica individual de um modelo de corpo determinado socialmente $e$ influenciado por uma cultura carioca e por valores modais da aparência física. Assim é que Malysse desenvolve seu artigo falando do estereótipo ideal da aparência física e suas consequências principalmente junto às classes médias da sociedade brasileira, analisando, entre outros, espaços públicos, academias de musculação, mídia, 'profissionais do corpo' (personal trainers) e moda. Em seu artigo, questões como distinção social, relações de gênero e usos sociais do corpo são privilegiadas. Uma das importantes conclusões do autor é a de que "as representações da aparência nas cenas sociais mostram que a semiótica da aparência muscular se tornou hoje, no Brasil, quase mais significativa, tanto econômica quanto socialmente, do que as da cor e as de gênero" (p. 119). De acordo com Malysse, a 'malhação' é um "fato social total".

O artigo de César Sabino, "Anabolizantes: drogas de Apolo", trata do uso de anabolizantes em academias de musculação e ginástica da Zona Norte do Rio de Janeiro, junto a homens e mulheres de classe média e média baixa. Através de sua observação participante, o autor desvela o universo das academias, relacionando a visão de mundo dos praticantes de exercícios físicos com o uso das 'novas drogas', contribuindo para a compreensão de uma sociedade que valoriza uma estética masculinizante, virilizante e individualizante. A 'andolatria', expressão proposta por Sabino, seria a adoração por princípios morais e éticos presentes na 'masculinidade hegemônica'.

Em seu trabalho, o autor relata a busca intermitente da ciência por substâncias que otimizem a forma do corpo, modificando a morfologia individual, sempre valorizando uma imagem impositiva de masculinidade e juventude. A "Indústria da Saúde" é legitimada pelos 'discursos especializados' presentes nos meios de comunicação, o que leva, segundo Sabino, indivíduos comuns a investirem no consumo de "dietas, exercícios, anabolizantes, clínicas estéticas e academias". Para o autor, o "hedonismo racionalista" é produto de um "controle disciplinar sem par na história", levando a um tipo de "ascetismo" associado "à diversão e ao consumo" (p. 150).

Ao contrário dos usuários de 'tóxicos tradicionais', como maconha, cocaína, entre outros, os adeptos dos anabolizantes resguardamse em uma imagem construída, em que o autodomínio, a disciplina e a racionalidade associam-se com as 'representações de saúde' - um corpo forte e magro. Sabino chama, então, de "dionisíaca" a conduta dos usuários de drogas e de "apolínea" a dos usuários de anabolizantes, concluindo que essas 'novas drogas' vêm se 'enquadrando' dentro dos 'mesmos parâmetros' presentes no consumo e tráfico de entorpecentes, embora "o processo de utilização de tais drogas se realiza em contextos e visões de mundo diferentes daqueles comumente associados aos usuários tradicionais de tóxicos" (p. 164). Ao invés de subverter, seus usuários buscam se integrar à 'cultura dominante' e aos seus padrões estéticos.

O americano Alexandre Edmonds, como diz o dito popular, "mirou no que viu e acertou o que 
não viu". No Brasil, para pesquisar a cultura afrobrasileira e a construção da identidade nacional, o antropólogo deparou com o carnaval carioca e a tão festejada mania da cirurgia plástica. $O$ resultado é o interessante artigo "No universo da beleza: notas de campo sobre cirurgia plástica no Rio de Janeiro".

Durante um ano, Edmonds entrevistou pacientes e médicos, procurando compreender 0 significado da beleza na sociedade brasileira, mais especificamente a partir das cirurgias plásticas com fins estéticos. Entre diversas constatações, a de que a beleza, no Brasil, não passa pela ótica da políitica merece destaque. Segundo o autor, desde o início do século XX, antes mesmo da Segunda Guerra Mundial, a rinoplastia (cirurgia plástica no nariz) já suscitava discussões na sociedade americana sobre o caráter racista que se escondia por trás de uma intenção estética. $O$ 'nariz de judeu', assumido corajosamente nos anos 60 e 70 por Barbra Streisand, e o 'nariz negróide', renegado por Michael Jackson, seriam os principais pivôs dessa polêmica. No Brasil, ao contrário, tal tipo de cirurgia plástica não carrega nenhuma conotação racista. Enquanto nos Estados Unidos, de acordo com o autor, a beleza é 'politizada', no Brasil ela é 'nacionalizada' - daí implantes de silicone nas nádegas, por exemplo, exagerando o que o senso comum entende por 'preferência nacional'.

Também outras questões trouxeram sua contribuição ao trabalho de Edmonds, como a democratização da beleza, a crescente igualdade na competição feminina entre gerações diferentes no mercado afetivo-sexual e a mobilidade social associada à construção de uma identidade baseada no corpo, processos deflagrados, entre outras coisas, pela cirurgia plástica no Brasil.

'Morenos', 'gringos', 'brancos', 'branquelos' e 'farofeiros', entre outros tipos ideais das praias cariocas, são objeto de estudo do trabalho etnográfico de Patrícia Farias, relatado em "Corpo e classificações de cor numa praia carioca".

Realizando seu trabalho de campo nas areias cariocas que vão do Posto 9, ponto nobre da Zona Sul, até a menos prestigiada Praia Grande, na Zona Oeste, a antropóloga desenha um mapa e suas fronteiras simbólicas e sociais que se estabelecem no litoral do Rio, observando as representações e classificações da cor da pele de quem se expõe ao sol para 'pegar um bronzeado'. A partir de depoimentos de freqüentadores menos usuais e de habitués, que para a autora servem de modelo para uma determinada prática social e técnica corporal emblemáticas do carioca de praia, o artigo revela-se de grande contribuição para o melhor entendimento sobre as noções de 'morenidade' no Brasil.

Recorrendo a proeminentes cientistas sociais, como Bourdieu, Freyre, DaMatta, entre outros, Patrícia fala ainda de distinção, miscigenação e corpo.

A Revista Raça Brasil, dirigida a um público identificado como de classe média negra, é o foco do antropólogo Peter Fry para discutir a interação entre mídia e as representações sociais na construção de uma identidade racial brasileira. $O$ artigo "Estética e política: relações entre 'raça', publicidade e produção de beleza no Brasil" aponta para a contribuição dos publicitários, principalmente, no sentido de acabar com associações entre uma 'estética negra' e 'defeitos morais', modificando as representações sociais 'racistas' através de anúncios e produtos como a revista Raça Brasil, que se valem de um modelo de beleza negro em conformidade com uma "ideologia liberal-assimilacionista".

O corpo feminino e seu uso na bruxaria moderna é o tema desenvolvido por Andréa Osório no trabalho "O corpo da bruxa". Analisando o discurso de um grupo de bruxas e bruxos, além de material coletado em bibliografia especializada e na Internet, a antropóloga revela o caráter reformulador da prática da bruxaria, modernamente chamada de wicca, que inverte os valores tradicionais associados ao feminino e ao masculino como representações sociais. $O$ corpo da bruxa, segundo a autora, é dotado de um potencial mágico, exclusivamente feminino, inerente à capacidade transformadora do útero, que legitima positivamente sua dominação em relação aos homens, dentro do grupo estudado. Para Osório, as bruxas modernas vêm reafirmar o lugar da mulher na sociedade pós-feminista, mostrando que há algo mais do que o papel da reprodução e da maternidade em suas vidas sociais.

Encerrando a coletânea, José Luiz Dutra fala de masculinidade e moda no esclarecedor "Onde você comprou esta roupa tem para homem?: a construção de masculinidades nos mercados alternativos de moda". Tomando de empréstimo a pergunta jocosa anteriormente explorada por Roberto DaMatta, Dutra levanta importantes questões relativas à construção da masculinidade em nossa sociedade. Observando os chamados 'mercados alternativos' da moda, como o Mercado Mundo Mix e a Babilônia Feira Hype, o autor entrevistou freqüentadores e estilistas ligados a esses dois eventos, interpretando em seus discursos a relação dos 
homens com a moda. Uma de suas conclusões é que, mesmo dentro de critérios 'alternativos' e mais ousados presentes no discurso dos entrevistados mais 'modernos', pode-se encontrar um aspecto regulador no sentido de controlar o que é próprio para homens e o que é 'exagerado' ou mesmo 'efeminado'. O estigma da homossexualidade a partir do vestuário também surge de forma central no artigo de Dutra, revelando que esse controle social se exerce mais entre os heterossexuais, que 'ousam' menos do que os homossexuais e bissexuais.

Cláudia da Silva Pereira Universidade Federal do Rio de Janeiro 